\title{
RESOLUÇÃO DE PROBLEMAS E CONSTRUÇÃO CONJUNTA DE CONHECIMENTO NA FALA-EM- INTERAÇÃO EM CENÁRIO DE DESENVOLVIMENTO TECNOLÓGICO
}

\author{
PROBLEM SOLVING AND JOINT CONSTRUCTION \\ OF KNOWLEDGE IN TALK-IN-INTERACTION IN A \\ TECHNOLOGICAL DEVELOPMENT SCENARIO
}

\section{Andréia Kanitz Pedro Garcez ${ }^{* \star}$}

\section{RESUMO}

Com vistas à qualificação do que sejam momentos de construção conjunta de conhecimento, descrevemos situadamente aqui a atividade interacional de resolução de problemas em cenário de desenvolvimento de tecnologia de ponta, onde, em contraste com as salas de aula, não há quem detenha de antemão os conhecimentos requisitados. Examinamos um segmento de resolução de problema, representativo do conjunto de instâncias identificadas em corpus de 60 horas de gravações audiovisuais geradas em laboratório de tecnologia voltado à produção de materiais biomédicos. A atividade de resolução de problema é descrita enquanto instância interacional em que há um obstáculo a ser transposto por todos os participantes envolvidos na interação. Diante dos problemas e da necessidade iminente de resolvê-los, os participantes engajam-se no trabalho de construção conjunta de conbecimento, sendo essa construção observável nas ações que os próprios participantes realizam para os fins práticos de retomada das atividades que vinham realizando. Esse exame situado de experiência vivida de produção conjunta de conhecimento pode servir de referência para projetos de trabalho e aprendizagem em pedagogias ativas.

Palavras-chave: resolução de problemas; construção conjunta de conhecimento; interação.

\section{ABSTRACT}

In order to substantiate what are moments of joint knowledge construction, we seek to describe here an instance of interactional problem-solving activity in a state-of-the-art technology development setting, where oftentimes, in contrast to classrooms, no one

\footnotetext{
* Instituto Federal de Educação, Ciência e Tecnologia do Rio Grande do Sul, IFRS Bento Gonçalves, RS, Brasil. andreia.kanitz@bento.ifrs.edu.br Orcid: https://orcid.org/0000-0001-7056-9065

** Universidade Federal do Rio Grande do Sul, UFRGS, Porto Alegre, RS, Brasil pedrom.garcez@ ufrgs.br

Orcid: https://orcid.org/0000-0001-8642-678X
} 
displays received knowledge. We examine an interactional segment featuring problemsolving which is representative of the set of instances identified in a 60-hour corpus of audiovisual recordings generated in a technology laboratory dedicated to the production of biomedical materials. The problem solving activity is described as an interactional instance where there is an obstacle to be overcome by all participants involved in the interaction. Faced with problems and the need to solve them, participants engage in the work of joint knowledge construction, and this construction is observable in the actions they perform for the practical purposes of resuming the activities they had been performing. We offer this situated examination of lived experience of joint knowledge production as possible reference for educational projects in active pedagogies.

Keywords: problem solving; joint construction of knowledge; interaction.

\section{RESOLUÇÃO DE PROBLEMAS EM UM CENÁRIO DE DESENVOLVIMENTO TECNOLÓGICO: O PONTO DE PARTIDA DO INTERESSE INVESTIGATIVO}

Poucos objetariam à asserção de que aprendemos muito com nossos amigos ou discordariam da afirmação de que existem muitos espaços não escolares em que aprendemos com os outros ao participarmos de variadas atividades sociais. Neste artigo, partimos justamente da conviçcão de que a aprendizagem constitui uma realização socialmente construída, flagrável em variadas atividades cotidianas. Para além disso, entendemos que interessa compreender como se dá a produção de conhecimento fora de eventos-aula para subsidiar a concepção de tarefas pedagógicas orientadas pelas assim chamadas "pedagogias ativas", organizadas em torno de projetos de trabalho ou resolução de problemas (BUCK INSTITUTE FOR EDUCATION, 2008).

Ainda assim, juntamos nossos esforços aos estudos que têm buscado descrever e demonstrar, pela análise detida de dados interacionais, como "os seres humanos se desenvolvem por meio de sua participação variável nas atividades socioculturais de suas comunidades" (ROGOFF, 2003, p. 38) e como isso se dá no plano da organização da fala-em-interação, dando especial atenção a cenários e eventos institucionais escolares, em que os participantes se encontram reunidos para "fazer o trabalho de aprender" (GARCEZ, 2010, p. 5). Esse conjunto de estudos demonstrou que o trabalho de construção de conhecimento escolar, até mesmo nas situações mais especiais, envolve muitas vezes a construção de conhecimento guiada por um participante que, na condução das atividades pedagógicas, se coloca como quem já conhece aquilo que está sendo construído (GARCEZ, 2006; GARCEZ; FRANK $;$ KANITZ, 2012a). Nesses casos, tal participante conduz e organiza as ações dos demais no trabalho de construção conjunta de conhecimento de modo que alcancem o conhecimento que ele domina. 
As reflexões tecidas no âmbito desse conjunto de estudos suscitaram a indagação sobre como o mesmo ocorreria em outros cenários, em que, diferentemente do que geralmente ocorre, por exemplo, em salas de aula convencionais, não houvesse um participante na posição de quem domina previamente o conhecimento a ser produzido, guiando e organizando as ações dos demais. A partir disso, surgiu o interesse por conhecer e compreender como se dá a construção de conhecimento na fala-em-interação entre participantes "que (diversamente do que se passa entre alunos e professores), não estivessem produzindo de novo conhecimento recebido, mas sim estivessem necessariamente produzindo conhecimento efetivamente novo em conjunto uns com os outros" (GARCEZ, 2010, p. 6).

O interesse por investigar um tal cenário de produção de conhecimento nos levou a um grupo de pesquisa em engenharia reversa atuante em um Centro de Tecnologia de uma universidade pública de que havíamos tido notícia e que estava dedicado a desenvolver stents ${ }^{4}$ para implantes pulmonares no tratamento de doenças cardiorrespiratórias. Interessava a esses pesquisadores à época "quebrar" a patente da prótese para que fosse possível a produção doméstica de produtos cuja aquisição dependia até então da importação a altos custos.

Semelhantemente ao que se almeja no contexto escolar da sala de aula, o objetivo maior do trabalho entre os pesquisadores desse Centro de Tecnologia é também a produção de conhecimento. No entanto, diferentemente do que se observa em grande medida nas salas de aula tradicionais, muitas vezes nenhum dos participantes nesse cenário de desenvolvimento de tecnologia detém previamente o conhecimento necessário para dar conta das atividades em que se engajam. Além disso, nenhum dos participantes atua de antemão como organizador das ações dos demais. Nesse Centro de Tecnologia, todos os participantes organizam suas ações em torno de atividades vinculadas aos seus projetos de trabalho no laboratório e, à medida que se deparam com as demandas emergentes dessas atividades, se autorregulam e empreendem esforços conjuntamente para dar conta de tais demandas.

Ao longo do trabalho de campo, tornaram-se relevantes - e dignas de espaço privilegiado nos diários - diversas situações em que os participantes lidavam com problemas emergentes do enfrentamento de suas tarefas práticas enquanto pesquisadores. Assim, neste artigo, apresentamos e analisamos uma instância de resolução de problemas, concebida aqui não apenas como construto teórico do analista, mas como uma instância interacional na qual os próprios participantes envolvidos

1. Um stent é uma endoprótese expansível, um tubo (geralmente de metal, principalmente nitinol, aço e ligas de cromo e cobalto) perfurado que é inserido em um conduto do corpo para prevenir ou impedir constrição e obstrução de fluxo. 
destacam um problema a ser enfrentado e engajam-se conjuntamente na sua superação. Nisso, orientam-se por meio de suas próprias ações para a situação como sendo uma instância de resolução de problema.

Nesses termos, apresentamos, por meio de uma metodologia focada na análise interacional, (a) uma descrição situada das ações que constituem a atividade interacional de resolução de problemas nesse cenário e (b) uma análise da relação de tal atividade com momentos de construção conjunta de conhecimento, em que há engajamento conjunto dos participantes nessa produção.

\section{A ANÁLISE DA CONVERSA ETNOMETODOLÓGICA: UMA PERSPECTIVA SOCIAL DE ORGANIZAÇÃO DAS INTERAÇÕES E DE COGNIÇÃO}

Compreender como os atores sociais se organizam para juntos produzirem ações pelo uso da linguagem constitui preocupação central de estudos que, como a presente pesquisa, orientam-se pela perspectiva teórico-metodológica da Análise de Conversa Etnometodológica (ATKINSON; HERITAGE, 1984; GARCEZ, 2008; LODER $\left._{i} J U N G, 2008\right)$. Voltada para o estudo da ação social humana situada no espaço e no decorrer do tempo real, a ACE constitui um desenvolvimento da teoria social proposta por Harold Garfinkel sob o rótulo de Etnometodologia (GARFINKEL, 1967; GARCEZ, 2008), cujo interesse central consiste justamente em compreender "como os atores sociais vêm a saber, e saber em comum, o que estão fazendo 2 " (HERITAGE, 1984, p. 76). Tal interesse decorre do entendimento de que a manutenção da inteligibilidade entre as pessoas acerca do que estejam fazendo no curso das atividades de uso da linguagem em que se engajam é fruto de um trabalho social e interacional intenso dos interagentes em busca da construção dessa intersubjetividade.

Operando com esse entendimento, estudos em ACE buscam investigar e compreender os procedimentos/métodos utilizados pelos atores sociais para produzirem conjuntamente ações pelo uso da linguagem e levarem adiante as atividades em que se engajam. A descrição de tais procedimentos se dá por meio da análise do que cada interagente faz no seu turno de fala após a produção do turno de fala de outro. Tal análise se sustenta nas premissas de que (a) o turno de fala que um interagente produz é orientado a um turno de fala precedente; (b) a ação realizada por meio de um turno de fala projeta uma próxima ação relevante (por exemplo,

2. How do social actors come to know, and know in common, what they are doing and the circumstances in which they are doing it? (Tradução reproduzida de FRANK, 2010, p. 16). 
um convite projeta uma recusa ou uma aceitação); (c) a produção de uma próxima ação relevante por um interagente revela seu entendimento da ação precedente e, portanto, estabelece interacionalmente o entendimento comum a respeito do que os interagentes estejam fazendo conjuntamente (SACKS; SCHEGLOFF; JEFFERSON, 1974; GARCEZ, 2008). Portanto, é pela análise sequencial das ações que se pode verificar os procedimentos por meio dos quais os participantes constroem e estabelecem um entendimento comum acerca do que estejam fazendo num exato aqui-e-agora de uma interação.

Partindo desse pressuposto, os estudos em ACE têm operado com um entendimento próprio de cognição. Desde essa perspectiva, o que os participantes sabem é o que eles demonstram e exibem saber em comum ao mobilizarem ações sequencialmente organizadas para levar adiante as atividades sociais de uso da linguagem em que se engajam. Trata-se de uma perspectiva de cognição enquanto realização social (SCHEGLOFF, 1991; ANTAKI, 2006; ABELEDO, 2008; GARCEZ; FRANK; KANITZ, 2012b; ABELEDO et al., 2014), em que o conhecimento é compreendido como uma realização pública, instanciada na interação entre os atores sociais mediante o uso da linguagem pela exibição da compreensão e pela produção de entendimento do que fazem em cada aqui-e-agora interacional. Nessa perspectiva, cognição, linguagem e interação guardam, assim, estreita relação (ABELEDO, 2008, p. 28), pois se compreende que a cognição, ao contrário de ser individual, é socialmente compartilhada e indissolúvel do uso da linguagem em interação. Nesse sentido, Abeledo (2008) aponta que

não é suficiente considerar a cognição como um conjunto de capacidades e processos individuais e autônomos, como também é limitador enxergar a linguagem como um conjunto de recursos manipuláveis para a codificação de mensagens, que só no momento da sua emissão na interação adquirem dimensão social. (p. 28)

A cognição, assim, longe de se referir tão-somente a conhecimentos abstratos depositados de modo isolado na mente dos indivíduos, é concebida como socialmente distribuída, sendo, assim, exibida no trabalho interacional dos atores sociais engajados na construção e manutenção de um mundo em comum ou de um conhecimento mantido em comum por meio de uma série de práticas interacionais mediadas pelo uso da linguagem e orientadas para a confirmação, modificação e ampliação desse conhecimento (SCHEGLOFF, 1991, p. 152; ABELEDO, 2008, p. 28; ABELEDO et al., 2014).

Dado, então, o entendimento de que a construção de um mundo em comum entre os participantes constitui uma realização social instanciada na interação, é na fala-em-interação que a produção e manutenção de um conhecimento 
compartilhado entre os atores sociais será, assim, investigada. É, portanto, tarefa do analista da conversa observar e analisar as práticas, ações e métodos dos quais os participantes da fala-em-interação se valem para demonstrar uns aos outros o que sabem ou conhecem em comum.

Portanto, desde o ponto de vista adotado no presente trabalho, o que os participantes sabem ou deixam de saber é o que eles próprios demonstram e exibem (não) saber em comum ao realizarem ações sequencialmente organizadas com o propósito de levar adiante as atividades particulares de uso da linguagem em que se engajam. $\mathrm{O}$ que os participantes sabem constitui, assim, uma questão prática, que depende dos propósitos da atividade que está sendo realizada e do que os participantes fazem para reconhecer uma cognição (ANTAKI, 2006). Esse entendimento permite abordar a construção conjunta de conhecimento a partir do que os participantes fazem em cada evento interacional, levando em conta o caráter situado/particular da interação.

\section{CONSTRUÇÃO CONJUNTA DE CONHECIMENTO NA FALA-EM-INTERAÇÃO EM CENÁRIOS DE PRODUÇÃO DE CONHECIMENTO}

Compreender e precisar os métodos utilizados pelos participantes de encontros sociais para produzirem conhecimento conjuntamente tem constituído o interesse central de pesquisa de estudos de fala-em-interação social que, como o presente, adotam o entendimento de cognição enquanto realização social, instanciada na interação (TE MOULDER; POTTER, 2005; VAN DIJK, 2006; STIVERS et al., 2011).

Compartilhando desse interesse, trabalhos desenvolvidos no âmbito do nosso Grupo de Pesquisa enfocaram práticas de organização de salas de aula em cenários escolares diversos que demonstram e refletem um entendimento de aprendizagem como construção conjunta de conbecimento (ver GARCEZ; FRANK; KANITZ, 2012a). A investigação realizada por Abeledo (2008) sobre as práticas utilizadas por participantes de uma sala de aula de Espanhol como língua estrangeira para produzir e demonstrar o trabalho de fazer aprendizagem de vocabulário trouxe uma importante contribuição ao definir o trabalho de fazer aprender - nos termos da presente pesquisa, de construir conhecimento com o outro - como uma "realização pública, emergente e contingente" (ABELEDO, 2008, p. 160), produzida conjuntamente pelos participantes para realizarem as atividades em que eles se engajam no aquie-agora das interações, "observável nos métodos que eles utilizam para exibir publicamente o trabalho de fazer aprendizagem" (ABELEDO, 2008, p. 138). Trata- 
se, assim, de uma realização que (a) resulta da ação conjunta dos participantes de uma interação; (b) é observável nas ações que os participantes mobilizam para dar conta de objetos de conhecimento tornados relevantes por eles próprios; (c) é produzida para os fins práticos de realização das atividades em curso na interação (ABELEDO, 2008; GARCEZ; SALIMEN, 2011). Segundo Abeledo et al. (2014), portanto, observar e descrever o trabalho de aprender, entendido não como o acúmulo individual de conhecimento de uma língua enquanto objeto de aprendizagem, mas sim como um trabalho interacional inseparável da participação pelo uso da linguagem, um trabalho que (re)organiza as relações de pertencimento (p. 138). É no aqui-eagora, portanto, que o conhecimento é construído conjuntamente por meio das ações mobilizadas pelos atores sociais para atender aos fins práticos, contingentes e emergentes das atividades em que se envolvem na interação.

O entendimento de construção de conhecimento enquanto realização pública, emergente e contingente, produzida pelos participantes para dar conta das atividades em que eles se engajam no aqui-e-agora das interações tem sido o sustentado não só em estudos realizados em cenário escolar (GARCEZ; FRANK; KANITZ, 2012a), mas também em cenários de atuação profissional (por exemplo, ver GOODWIN, 1994; GOODWIN, 1997; SUCHMAN, 2000; WHALEN; VINKHUYZEN, 2000; BRASSAC et al., 2008; KOSCHMAN et al., 2011; HINDMARSCH, REYNOLDS; DUNNE, 2011; GARCEZ; FRANK; KANITZ, 2012b; KANITZ; FRANK, 2014). Na esteira desse interesse, tal conjunto de estudos tem sustentado também a compreensão de que são as demandas profissionais práticas que organizam as atividades realizadas nos diferentes ambientes de trabalho e que, por sua vez, mobilizam os profissionais a se engajarem no trabalho interacional conjunto de construção de conhecimento. Desde a perspectiva articulada a partir desse conjunto de estudos, o trabalho de construção conjunta de conhecimento relaciona-se, assim, estreitamente às demandas de trabalho que se colocam aos atores sociais no enfrentamento das tarefas relacionadas ao exercício de suas atividades profissionais. São elas que mobilizam o trabalho interacional conjunto de construção de conhecimento pelos profissionais.

Nesses termos, adotamos aqui um entendimento de construção conjunta de conbecimento enquanto realização social pública estreitamente relacionada às demandas de trabalbo, responsáveis por engajar os participantes nessa construção de caráter não só situado e emergente, como também consequente, porque é do êxito nesse trabalho de construção conjunta que depende a continuidade das atividades em que se envolvem os profissionais. Ademais, soma-se a esse entendimento a compreensão do trabalho interacional de construção conjunta de conhecimento formulada por Kanitz e Frank 
(2014) enquanto realização que envolve (a) a produção de um avanço relevante na atividade em que os participantes estão engajados e (b) a manifestação de satisfação dos participantes com relação ao avanço produzido.

\section{O TRATAMENTO ANALÍTICO DOS DADOS: SEGMENTAÇÃO, TRANSCRIÇÃO E ANÁLISE}

Na construção de uma coleção de dados para o presente trabalho, procedeu-se à visualização das 60 horas de registros audiovisuais. Ao total, foram identificadas 38 instâncias que apresentassem como semelhança a orientação dos participantes para o enfrentamento e superação de algum problema na realização da atividade em que vinham engajados. Procedeu-se à análise dos dados para (a) produzir uma descrição situada das ações que constituem a atividade interacional de resolução de problemas nesse cenário e (b) examinar a relação de tal atividade interacional com o trabalho de construção conjunta de conhecimento, privilegiando o que os próprios participantes demonstram ser sua perspectiva acerca do que está acontecendo em cada aqui-e-agora.

Verificou-se que, em boa parte das instâncias levantadas, o problema destacado pelos participantes era um obstáculo a ser enfrentado e superado conjuntamente por todos, já que demonstradamente nenhum deles possuía uma solução para a questão que a eles se colocava. Nesse conjunto que contempla a grande maioria das instâncias de resolução de problemas levantadas (31 ocorrências), observou-se que os participantes resolvem os problemas diante dos quais estão colocados (a) pela busca e confirmação conjunta de uma informação (10 ocorrências), (b) pela construção conjunta de um procedimento para a realização de alguma atividade (13 ocorrências), (c) pela elaboração conjunta de uma explicação para um fato (8 ocorrências). Neste artigo, analisamos um segmento interacional representativo desse grupo de ocorrências ${ }^{3}$.

\section{5. "QUÊ QUE É O ATAQUE ÉVERTON?": RESOLVENDO UM PROBLEMA PELA BUSCA CONJUNTA DE UMA INFORMAÇÃO}

Em uma das principais frentes de pesquisa em andamento no laboratório de tecnologia investigado à época do trabalho de campo para geração de dados

3. Além desse conjunto de instâncias, identificou-se, no entanto, também ocorrências em que o problema a ser superado não configurava um obstáculo a ser enfrentado e superado por todos os participantes. Nesse conjunto que contempla um total de sete ocorrências, o problema destacado por um participante é superado com ajuda de outro que detém a resolução para a questão. 
examinados aqui, os pesquisadores experimentavam obter, pioneiramente, por meio de metalurgia do pó ${ }^{4}$, uma liga metálica, composta de níquel e titânio, amplamente utilizada na produção de materiais biomédicos: o nitinol ${ }^{5}$. Nessa empreitada, os participantes buscavam determinar os parâmetros do processo de obtenção da liga. Dentre os parâmetros investigados estavam a temperatura e o tempo de aquecimento em forno a que devem ser submetidas as misturas de níquel e titânio para que ocorram adequadamente a ligação entre os metais e, assim, a formação completa da liga. Diferentes amostras, obtidas experimentalmente sob condições variadas de temperatura e tempo de aquecimento vinham sendo analisadas para fins de identificação das condições exitosas para a formação do nitinol.

No dado analisado a seguir, os pesquisadores Éverton e Luana encontramse justamente envolvidos no trabalho de análise metalográfica ${ }^{6}$ de duas amostras metálicas resultantes de tentativas experimentais de obtenção da liga. Por meio dessa análise, os participantes buscavam verificar se a formação do nitinol, de fato, ocorreu. O segmento interacional transcrito a seguir aconteceu após uma análise microscópica inicial das amostras, quando os participantes já se encaminhavam para uma etapa seguinte do trabalho: a realização do ataque químico - em que as amostras são mergulhadas em uma mistura composta por diferentes reagentes químicos, cuja ação possibilita a realização de um exame microscópico mais detalhado e aprofundado do material. É exatamente no momento de preparo da mistura para o ataque químico que os participantes se veem colocados diante de um problema que os impede de seguir adiante no trabalho de tratamento de suas amostras: falta-lhes a informação precisa da quantidade de cada um dos reagentes para a composição da mistura. Coloca-se, desse modo, aos participantes um problema a ser resolvido, a saber, encontrar e confirmar a informação da quantidade exata de cada um dos reagentes necessária para compor a mistura. Trata-se de uma instância de resolução de problema em que a busca e confirmação de uma informação constituem o foco da atividade para a qual os participantes passam a se orientar na interação (Quadro 1).

4. A metalurgia do pó é um processo de fabricação de peças metálicas pela aplicação de pressão sobre pós metálicos ultrafinos. Trata-se de um processo em franca expansão na atualidade em que a economia de material é levada ao extremo, com mínimas perdas de matéria-prima.

5. Nitinol é o nome comercial da liga composto pelos símbolos dos elementos químicos que a constituem (níquel $(\mathrm{Ni})$ e titânio $(\mathrm{Ti})$ ) e pela sigla do laboratório que a descobriu (NOL): nitinol. No Brasil, não há quem fabrique a liga, o que exige a sua importação a altos custos.

6. Por meio de uma análise metalográfica, busca-se identificar a constituição metálica de determinados materiais. As análises em geral são feitas em microscópios ópticos específicos, que permitem apenas a observação de superfícies perfeitamente planas e polidas. Em função disso, a preparação adequada das amostras, pelo cumprimento das etapas de polimento e ataque químico do material, tem grande importância na qualidade de uma análise. 
Quadro 1. Linha de tempo da geração de dados com localização cronológica do segmento.

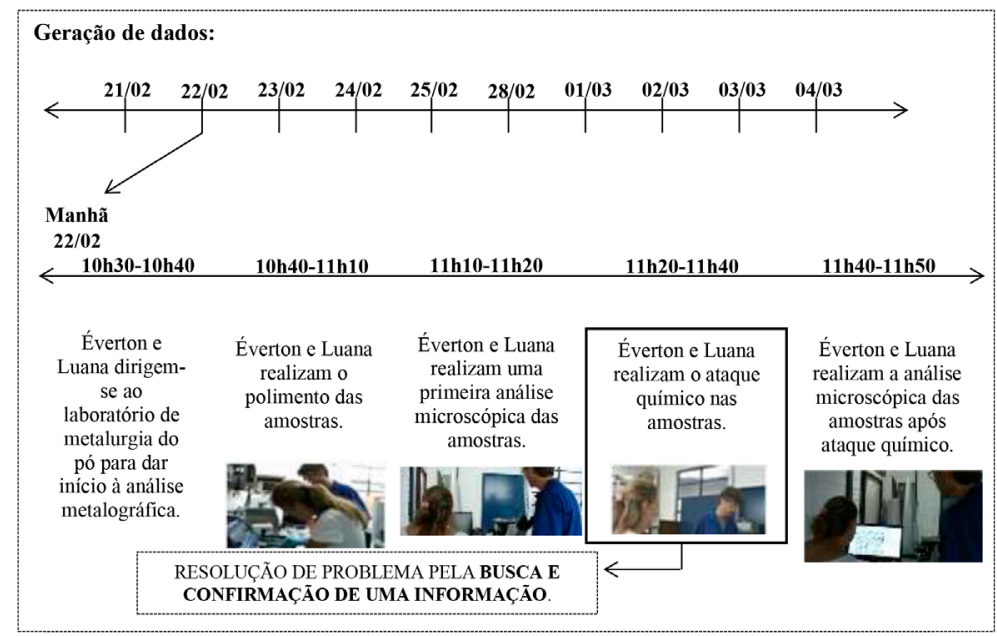

Fonte: KANITZ (2013).

O segmento interacional tem início quando a participante Luana, já orientada para a etapa de realização do ataque químico das amostras, solicita a Éverton a informação dos reagentes a serem utilizados para compor a mistura. Na sequência da interação, é com a necessidade de obtenção e confirmação exata dessa informação, levantada inicialmente por Luana e sustentada ao longo do segmento por Éverton, que os participantes passam a lidar, conforme acompanhamos a partir do excerto 1 abaixo.

\section{Excerto 1}

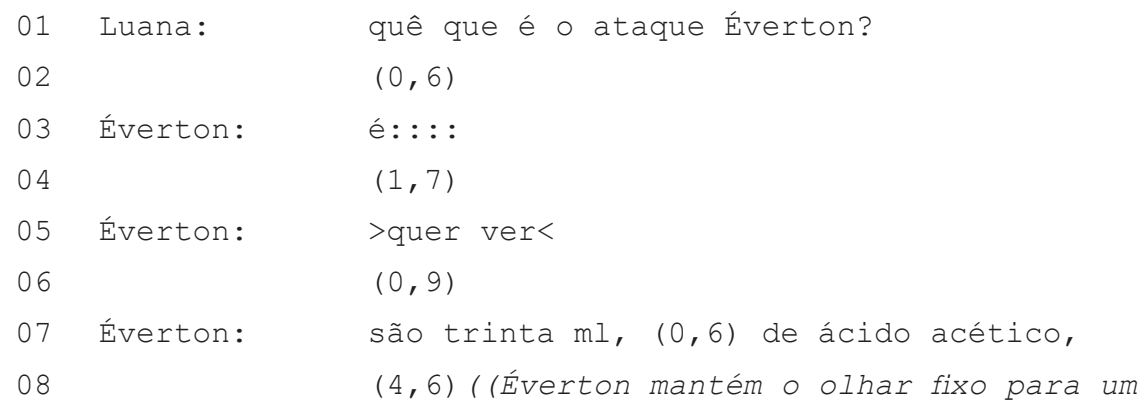


10 Éverton:

11

12 Luana:

13

14

15 Luana:

16

17

18

19 Éverton:

20

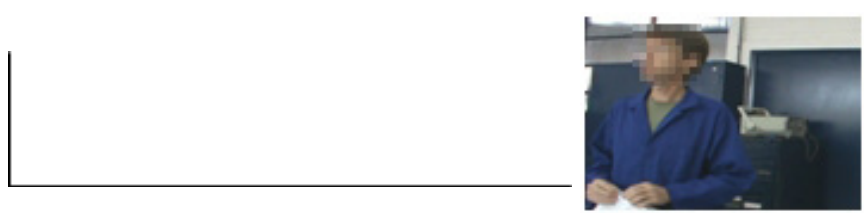

puta merda ((Éverton olha para baixo))

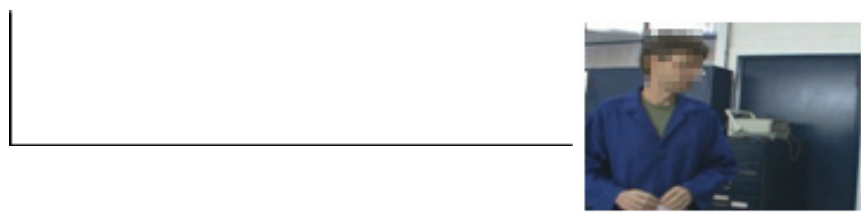

(.)

esqueceu? ((Luana direciona olhar para

Éverton, enquanto ele olha para baixo))

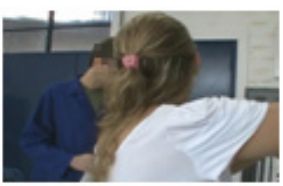

$(3,4)$

(quanto é)

$(7,1)$ ( Luana mantém olhar direcionado para Éverton, enquanto ele continua olhando para baixol)

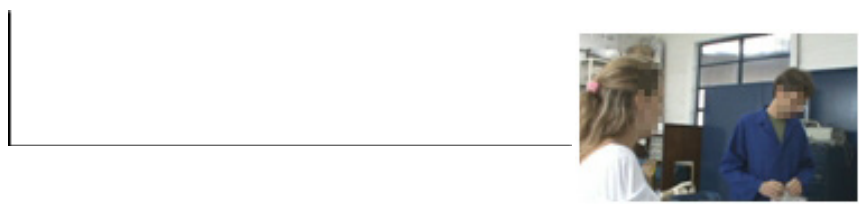

são trinta cinco e dois >é isso?< (lÉverton olha

para Luana) )

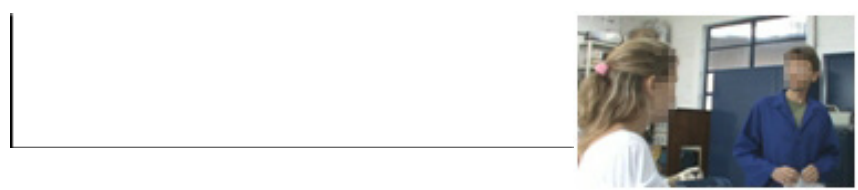


21

22 Éverton:

$(1,4)$ ((Luana eleva os ombros))

\section{puta >e agora Luana?<}

Orientado para o pedido de informação realizado por Luana acerca dos reagentes para compor a mistura do ataque químico ("quê que é o ataque Éverton?", linha 1), Éverton, nos turnos seguintes, passa a se orientar para a realização da próxima ação sequencialmente relevante: fornecer a informação solicitada por sua interlocutora. Ao longo dos três turnos que se seguem ao pedido de informação de Luana, o participante produz três tentativas de prover a informação solicitada, seguidas de pausas longas: "é: : : :", linha 3 ; “>quer ver $<$ ", linha 5; “são trinta $\mathrm{ml},(0,6)$ de ácido acético,", linha 7 . Luana, orientada para a incompletude da ação de seu interlocutor, expressa pelo alongamento de vogal (linha 3) e pela entonação em tom de continuidade (linha 7), não toma o turno, apesar das oportunidades de fazê-lo. É somente na linha 12, após outra elocução de Éverton ("puta merda", linha 10), que a participante produz um turno de fala em que se orienta para uma possível dificuldade por parte de seu interlocutor em fornecer a informação solicitada: "esqueceu?", linha $12 .^{7}$

Segue-se a isso outro longo período de pausa (linhas 14-18), intercalado por uma elocução breve de Luana, de transcrição duvidosa [“" quanto é)", linha 15], ao longo da qual Éverton mantém seu olhar direcionado para baixo, demonstrando ainda estar empenhado na busca pela informação que lhe foi solicitada. É somente na linha 19 que o participante propõe, de fato, uma resposta para o pedido de informação, resposta acerca da qual ele próprio demonstra, no entanto, estar inseguro, na medida em que a submete à confirmação de sua interlocutora: "são trinta cinco e dois >é isso?<”. Luana, embora não produza um turno de fala em resposta a esse pedido de confirmação, demonstra, ao elevar os ombros, estar em dúvida com relação à precisão da resposta produzida pelo interlocutor, o que leva Éverton a indagá-la, no turno imediatamente seguinte, acerca do que fazer, já que nenhum dos dois está certo da informação que lhes falta para compor a mistura a ser utilizada no ataque químico das amostras: "puta >e agora Luana?<", linha 22.

Sem uma resposta precisa acerca da quantidade de cada um dos reagentes a serem utilizados na composição da mistura para o ataque químico, os dois

7. Note-se que assim a sequência de ações aqui se distingue claramente do padrão canônico da interação de sala de aula, em que respostas hesitantes a pedidos de informação resultam em ações de avaliação realizadas pelo participante que fez a pergunta inicial, que, portanto, se torna publicamente uma pergunta de informação conhecida e não um pedido de informação como outro qualquer. 
participantes se veem colocados diante de um problema cuja resolução é condição sine qua non para que o ataque químico e a análise metalográfica das amostras possam ser levados adiante. Trata-se de um problema que se instaura de modo contingente na interação entre os participantes quando Éverton, selecionado por Laura como um possível conhecedor da informação que ela está buscando, demonstra não estar seguro da resposta. Há, portanto, uma demanda de busca e confirmação de uma informação que se coloca aos participantes na sequência da interação.

A partir desse momento, os participantes passam a lidar com essa demanda, engajando-se na busca e confirmação da informação exata da quantidade dos reagentes para o ataque químico. É Luana quem dá o passo inicial nesse sentido, quando questiona Éverton acerca de onde a informação poderia estar registrada, conforme acompanhamos a partir do excerto 2 abaixo.

\section{Excerto 2}

23

24 Luana:

25

26 Éverton:

27

28 Éverton:

29

30 Luana:

31

32 Éverton:

33

34 Éverton:

35

36 Éverton:

37

38 Éverton:

40

$$
(1,2)
$$

onde tem isso anotado?

$(2,7)$

eu tenho no meu computador

$(0,8)$

eu vou lá ver

$(1,3)$

'tá ${ }^{\circ}$

(.)

é : :

$(5,1)$

porque eu faço meia.

$(1,3)$

é: : :

$(2,0)$

aí eu não sei se o ci: : $(0,9)$ se ○ cinco

$(1,3)$ e o dois $(0,7)$ são já divididos, $(1,4)$

>eu não sei se é< trinta cinco e dois, ou se 
41

43

44 Éverton:

45 Luana:

46

47 Éverton:

48

49 Éverton:

50 como eu faço a metade eu faço quinze cinco e

dois

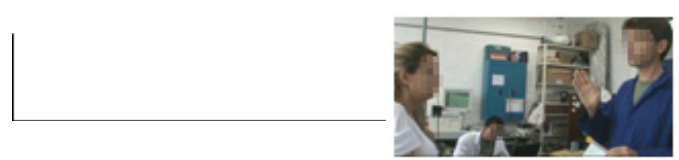

$(2,5)$

>tu não leu isso?<

não (Luana e Éverton baixam a cabeça))

(.)

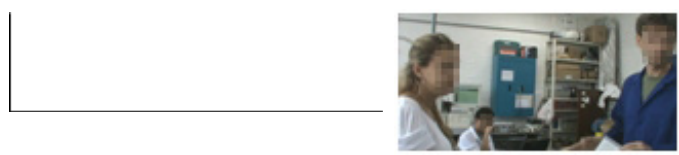

`eu vou lá verº

$(1,6)$

espera aí

$(1,4)$

Diante do novo pedido de informação de Luana ("onde tem isso anotado?", linha 24), em que a participante já demonstra orientação para a necessidade de resolução do problema diante do qual estão colocados, Éverton afirma que a informação que lhes falta estaria disponível em seu computador ("eu tenho no meu computador", linha 26), localizado em outra sala na outra ponta do prédio em que estavam ${ }^{8}$. Em alinhamento à orientação para a resolução do problema demonstrada por sua interlocutora, o participante anuncia que vai a outra sala verificar a informação ("eu vou lá ver", linha 28), com o que Luana concorda ("otáo", linha 30).

Logo em seguida, Éverton justifica para Luana sua dificuldade em prover a informação por ela solicitada, explicitando novamente incerteza acerca da quantidade exata de cada reagente para compor a mistura: "porque eu faço meia.", linha 34; "aí eu não sei se o ci: : se o cinco e o dois são já divididos, >eu não sei se é< trinta cinco e dois, ou se

8. Para verificar a distância aproximada entre o laboratório de metalurgia do pó e a sala ocupada pelos pesquisadores, ver Figura 1. 
como eu faço a metade eu faço quinze cinco e dois", linhas 38-42. Éverton, no próximo turno, ainda verifica se Luana não teria lido essa informação (">tu não leu isso?<", linha 44), ao que ela responde "não" (linha 45).

De fato, a informação de que os participantes necessitam, isto é, a quantidade exata de cada um dos reagentes, precisa ser confirmada. Diante disso, Éverton, logo em seguida, retoma a proposta de ir verificá-la em seu computador ("o eu vou lá ver ${ }^{\circ}$, linha 47; "espera aí", linha 49), proposta para qual Luana se orienta, apontando e submetendo ao interlocutor a possibilidade de se poder obtê-la em um livro, conforme acompanhamos no excerto 3 abaixo:

\section{Excerto 3}

51 Luana:

não é num livro >é um livro?<

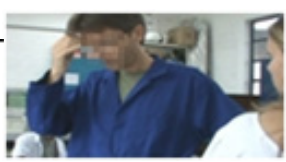

52 Éverton:

tem num: : aqui num pôster com um trabalho

que eles apresentaram uma [vez aqui]

54 Luana:

[aqui tem] um $>$ não é $<=$

55 Éverton:

=tem aqui?

$(0,7)$

57 Luana:

58

acho que é aqui ((Luana caminha em direção à

59

porta da sala ao lado))

60

$(1,7)$ ((Luana conduz Éverton até uma sala ao lado))

61 Luana:

(esse aqui é sobre o nitinol) ((Luana

caminhando em direção ao pôster fixado na parede

da sala ao Iado) )

65 Éverton: .hmmm

67 Éverton:

( ${ }^{\circ}$ esse não é eu acho) (lolhando para o 
pôster))

68

69

70

71

72

73

74

75

76

77

78

79 Luana:

80

81 Éverton:

82
Luana :

Luana:

Éverton:

Luana:

Éverton:

Luana:

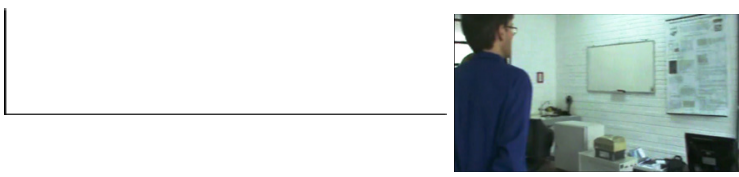

$(1,8)$

é

$(4,0)$

eu não lembro se a gente tem. tá lá na sala eu

acho

é

liga pra lá

$(7,3)$

sabe aquele que tava lá na parede lá na

frente a: : da chave de luz? tu [sabe?

[sim. mas daí

tira [ram de lá] =

=>não tá mais lá<

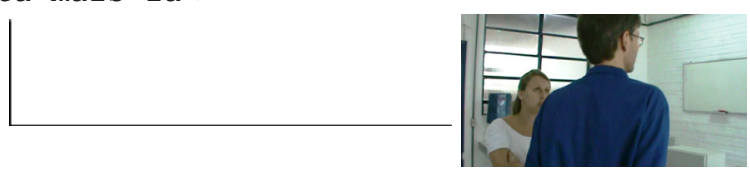

Indagado por Luana acerca da possibilidade de se poder encontrar a informação buscada em um livro ("não é num livro >é um livro?<", linha 51), Éverton afirma que seria possível obtê-la no pôster de um trabalho ("tem num: : aqui num pôster com um trabalho que eles apresentaram uma [vez aqui] ", linhas 52 e 53). Luana, em curta sobreposição com seu interlocutor, sugere, então, que o pôster estaria no laboratório em que os dois se encontravam naquele momento ("aqui tem um >não é<", linha 54). Éverton, demonstrando desconhecer a informação apresentada pela interlocutora, questiona-a a respeito ("tem aqui?", linha 55), ao que Luana responde "acho que é aqui" (linha 57), já se dirigindo para uma sala ao lado da que estavam.

Luana conduz Éverton até o pôster que poderia apresentar a informação da quantidade dos reagentes para a realização do ataque químico (“" (esse aqui é sobre o nitinol)", linha 61). Depois de juntos verificarem o cartaz, os dois 
participantes concordam, entretanto, que a informação por eles procurada não se encontra registrada ali e que, portanto, não se trata do pôster referido inicialmente por Éverton ("oesse não é eu acho)", linha 67; "é", linha 70).

Luana e Éverton, na sequência da interação, ainda conversam sobre a possível localização do pôster que, de acordo com Éverton, trazia a informação que precisam confirmar para a realização do ataque químico (linhas 72-75). Nas linhas 77 e 78, Éverton descreve para Luana a localização do objeto na sala: "sabe aquele que tava lá na parede lá na frente a: : da chave de luz? tu sabe?”. Sua interlocutora se reconhece o referente e informa ao colega, no entanto, que o pôster havia sido retirado de lá: "sim. mas daí tiralram de lá >não tá mais lá<", linhas 79, 80 e 82.

Diante dessa tentativa frustrada de localização e confirmação da informação, Éverton apresenta outra proposta para a resolução do problema: a busca pela informação em algum artigo publicado no site do laboratório. Luana novamente acompanha o colega de pesquisa em mais essa tentativa de resolução do problema, tentativa na qual finalmente os participantes obtêm êxito, conforme acompanhamos no quarto e último excerto abaixo.

\section{Excerto 4}

\section{((3 Iinhas de transcrição omitidas))}

86 Éverton: deve ter um trabalho, ou: : algum trabalho aí

$87 \quad$ é: : é: :

$88 \quad($.

89 Éverton: >espera aí< >tinha que ver< no site do ldtm

90 (.)

91 Éverton: que: que computador será que a gente pode usar ((Luana e Éverton voltam para a sala))

147 Éverton:

transcrição omitidas)) vamos ver ((localiza o site do ldtm)) $(16,0)$ ((Éverton e Luana olham para a tela do

computador; Éverton abre link com as publicações 
151 Éverton:

152

153 Luana:

154

155 Éverton:

156

157

158

159 Éverton:

160

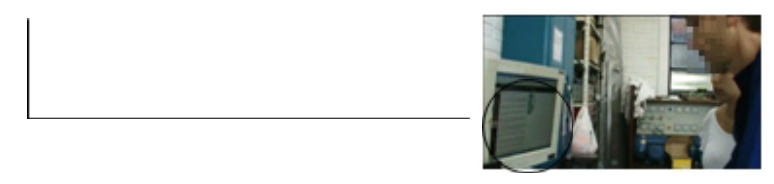

( ${ }^{\circ}$ nós estamos: : $\left.{ }^{\circ}\right)$

$(1,3)$

não é dois mil e dez?

$(1,5)$

eu tentei dois mil e: : >acho que dois mil e

dez não era<

$(1,7)$ ( (Éverton volta para página com os links

das publicações por ano))

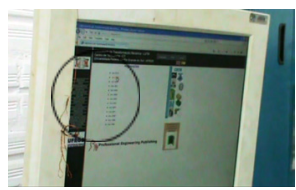

vamos ver (labre a página com as publicações do ano de dois mil e dez))

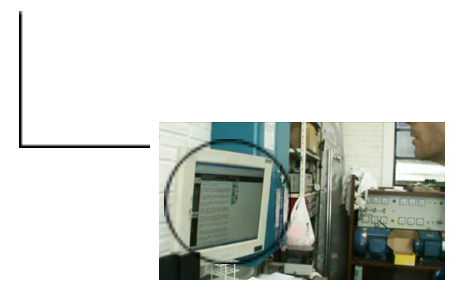

161 Éverton:

>vê se você acha alguma coisa aí

164 Luana:

que fala de nitinol<

$(0,4)$

m.hm o estudo da obtenção de espuma de

alumina, ((Luana lê na tela do computador))

167 Éverton: $(0,7)$

caracterização parcial da liga, ( lê na tela do computador)) 


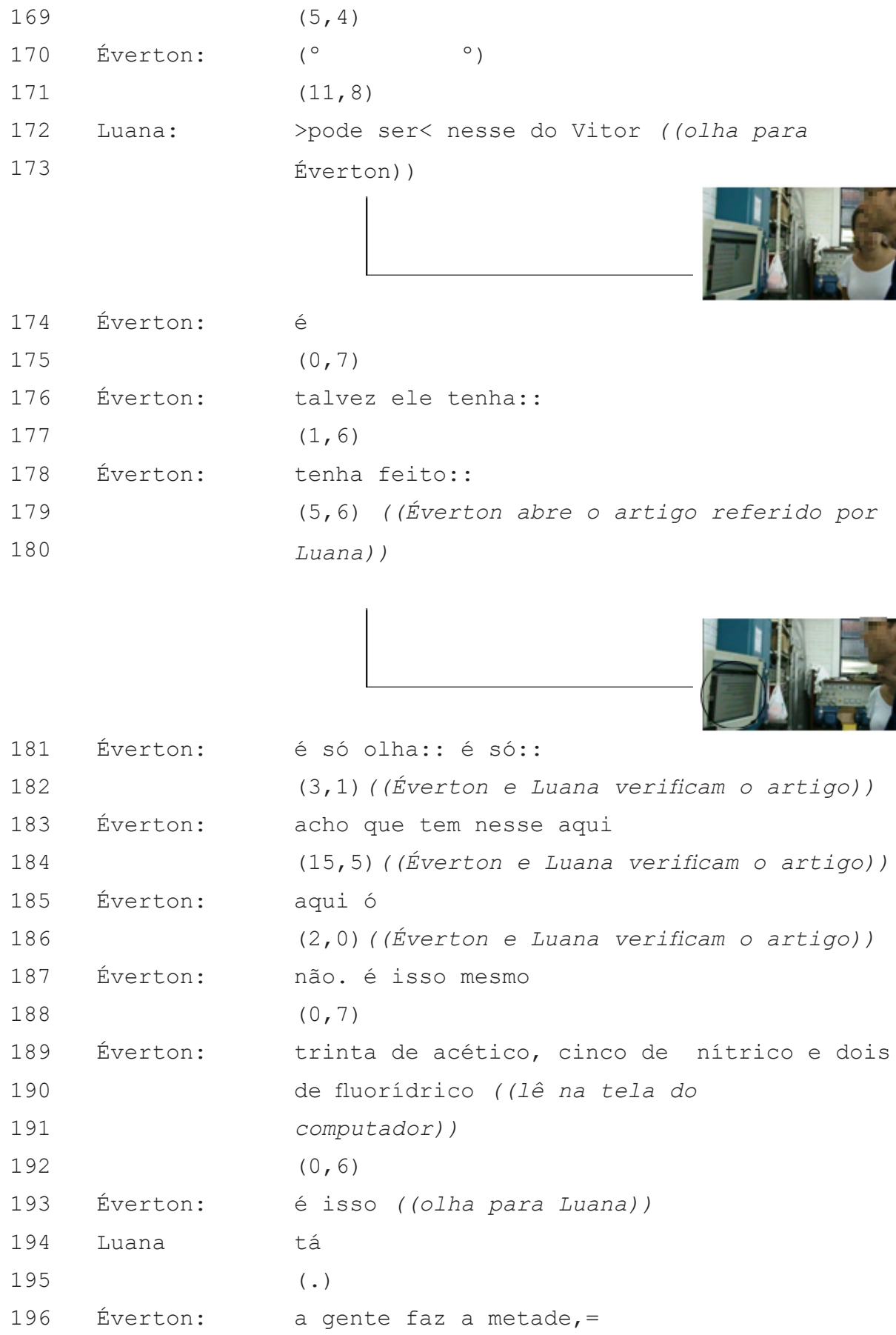

169

170 Éverton:

171

172 Luana:

173

174 Éverton:

175

176 Éverton:

177

178 Éverton:

179

180

181 Éverton:

182

183 Éverton:

184

185 Éverton:

186

187 Éverton:

188

189 Éverton:

192

193 Éverton:

194 Luana

195

196 Éverton:

$(5,4)$

$\left({ }^{\circ} \quad{ }^{\circ}\right)$

$(11,8)$

>pode ser< nesse do Vitor (lolha para Éverton))

é

$(0,7)$

talvez ele tenha: :

$(1,6)$

tenha feito: :

$(5,6)$ ((Éverton abre o artigo referido por Luana))

é só olha:: é só: :

$(3,1)$ ((Éverton e Luana verificam o artigo)) acho que tem nesse aqui

$(15,5)$ ((Éverton e Luana verificam o artigo)) aqui ó

$(2,0)$ ( Éverton e Luana verificam o artigo)) não. é isso mesmo

$(0,7)$

trinta de acético, cinco de nítrico e dois de fluorídrico (llê na tela do computador) )

$(0,6)$

é isso ((olha para Luana))

tá

(.)

a gente faz a metade, = 


$\begin{array}{lll}197 \text { Luana: } & \text { =quinze, } \\ 198 & (0,9) \\ 199 \text { Éverton: } & \text { quinze, dois e meio e um } \\ 200 & \text { ((Luana e Éverton saem da frente do } \\ 201 & \text { computador e se preparam para realizar as } \\ 202 & \text { misturas dos componentes)) }\end{array}$

Logo após Éverton sugerir que a informação procurada poderia ser obtida em um trabalho ("deve ter um trabalho, ou: : algum trabalho aí é: : é: :", linhas 86-87) hospedado na página virtual do laboratório (">espera aí< >tinha que ver< no site do ldtm", linha 89), os dois participantes voltam para a sala em que se encontravam anteriormente à procura de um computador para poderem realizar a busca. Nas 54 linhas de transcrição omitidas, os participantes solicitam permissão para a utilização do computador disponível na sala, Éverton e Luana dão início à verificação das listas de publicações organizadas por ano de publicação, disponíveis na página do laboratório: "vamos ver", linha 147.

Éverton seleciona a lista de publicações do ano de 2009 para uma primeira verificação. Durante 16 segundos, os dois participantes verificam os títulos dos trabalhos publicados naquele ano, mantendo os olhares direcionados para a tela do computador. Na linha 153, depois de um turno de Éverton inaudivel ao transcritor, Luana sugere, por meio de uma pergunta, que o trabalho por eles procurado seja uma publicação do ano de 2010: "não é dois mil e dez?". Éverton orienta-se para a sugestão de sua interlocutora, procurando recordar qual página de publicações ele havia aberto: "eu tentei dois mil e: : >acho que dois mil e dez não era<", linhas 155-156. O participante, então, retorna para a página que contém os links dos trabalhos por ano de publicação e abre a lista de trabalhos publicados no ano de 2010, conforme sugerido por Luana.

Aberta a lista de publicações do ano de 2010, Éverton pede ajuda da interlocutora para localizar algum artigo sobre nitinol: "vamos ver", linha 159; ">vê se você acha alguma coisa aí que fala de nitinol<", linhas 161-162. Os dois passam a ler os títulos dos trabalhos (linhas 163-169). Na linha 172, depois de Éverton fazer referência a um trabalho que, segundo ele, podia conter a informação procurada (“( ${ }^{\circ}$ pode ser nesse ${ }^{\circ}$ )", linha 170), Luana sugere, então, um artigo publicado por um colega de laboratório como possível fonte para obtenção e confirmação da informação (">pode ser< nesse do Vitor", linha 172), o que Éverton endossa ("é talvez ele tenha: : tenha feito: :", linhas 174-178). 
Nos turnos seguintes, os participantes passam a se engajar na verificação dessa possibilidade apresentada por Luana. Éverton abre o artigo indicado pela interlocutora, e os dois juntos passam a verificá-lo na tela do computador. Éverton passa a dar indícios, por meio de seus turnos, de que, de fato, a informação procurada poderia estar disponível ali ("é só olha: : é só: :", linha 181; “acho que tem nesse aqui", linha 183; “aqui ó”, linha 185). É a partir da linha 187 que esses indícios se confirmam, quando Éverton finalmente encontra a informação da quantidade de cada um dos reagentes para compor a mistura para o ataque químico: "não. é isso mesmo", linha 187; "trinta de acético, cinco de nítrico e dois de fluorídrico", linhas 189-190; “é isso", linha 193.

Depois de Luana dar recibo da informação (“tá”, linha 194), Éverton ainda salienta que devem preparar meia mistura dos reagentes. Em imediata contiguidade ao turno de seu interlocutor, Luana inicia a transformação das medidas de cada um dos reagentes, produzindo um turno em tom de continuidade ("quinze, ", linha 197), que é completado por Éverton logo em seguida: "quinze, dois e meio e um", linha 199.

Mediante esforços conjuntos, os participantes conseguem, ao final desse segmento interacional, encontrar e confirmar a informação da quantidade exata de cada um dos reagentes para a realização do ataque químico das amostras sob análise: "quinze" ml de ácido acético, "dois e meio" ml de ácido nítrico "e um" $\mathrm{ml}$ de ácido fluorídrico. É de posse dessa informação que os participantes, então, retomam e dão seguimento ao trabalho de análise metalográfica das amostras de nitinol, suspenso inicialmente diante do problema da falta de informação precisa da quantidade de cada um dos reagentes para a composição da mistura.

No segmento analisado, portanto, o problema da falta de uma informação precisa acerca da quantidade de cada um dos reagentes para realizar o ataque químico se instaura de modo emergente na interação, suspendendo a atividade em andamento. É diante da dificuldade apresentada por Éverton em prover uma resposta segura para o pedido de informação realizado por Luana e do próprio desconhecimento da informação exibido pela participante ao realizar tal pedido e ao confirmar desconhecê-la quando indagada por seu interlocutor que os participantes se veem colocados frente a uma demanda contingente de resolução de problema pela busca e confirmação de uma informação crucial para que possam dar continuidade à atividade de tratamento das amostras em que estavam envolvidos. Vale frisar que é a necessidade de dar seguimento ao trabalho de análise metalográfica das amostras de nitinol que leva os participantes a engajarem-se na resolução do problema da falta de uma informação precisa sobre a quantidade dos reagentes para o ataque químico. 
É a demanda prática de retomada do trabalho de análise das amostras que mobiliza os participantes a se engajarem por cerca de sete minutos na resolução do problema que suspende a atividade que vinha sendo realizada.

Engajados nessa atividade de busca e confirmação de uma informação, Éverton e Luana realizam uma série de ações sequencialmente organizadas: pedem informações um ao outro, produzem justificativas, apresentam sugestões para localização da informação procurada, pedem ajuda um ao outro e, principalmente, numa orientação colaborativa de resolução do problema, atendem ao pedido de ajuda. Todas essas ações são implementadas tendo em vista a demanda de retomada do trabalho de análise das amostras, suspenso pela falta de uma informação crucial para sua realização. É essa demanda que compele Éverton e Luana a manterem um foco de atenção conjunto e a lançarem mão de um repertório de ações durante o segmento interacional até que encontram, finalmente, a informação que precisa ser confirmada para a retomada da atividade suspensa (Quadro 2).

Quadro 2. Quadro esquemático da atividade de resolução de um problema pela busca e confirmação de uma informação.

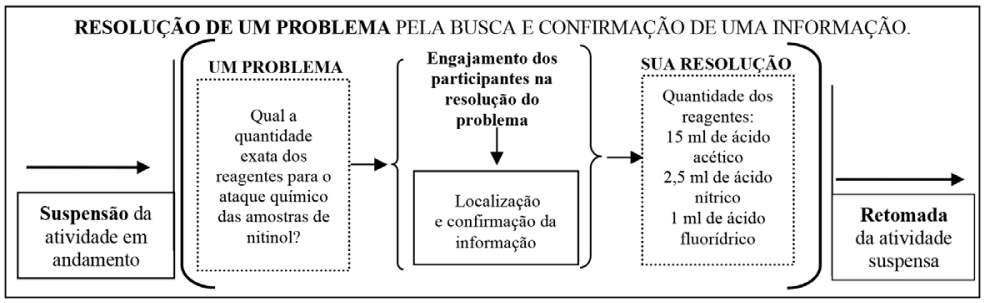

Fonte: KANITZ (2013)

Engajados na resolução do problema de busca e confirmação da informação exata da quantidade de cada um dos reagentes para o ataque químico, os participantes, argumentamos aqui, constroem conhecimento conjuntamente na medida em que, naquele exato aqui-e-agora, dão conta do objeto de conhecimento tornado relevante por eles próprios quando alcançam, mediante esforços conjuntos, a informação que resolve o problema diante do qual estavam colocados e que lhes possibilita dar seguimento ao trabalho de análise das amostras de nitinol que vinham empreendendo. Ao longo do segmento analisado, Éverton e Luana buscam, por meio de esforços interacionais conjuntos, dar conta de um problema tornado relevante por eles próprios desde o início do segmento e é mediante ações sequencialmente organizadas que eles progridem na resolução do problema, alcançando, por fim, um 
entendimento compartilhado acerca da quantidade exata de cada um dos reagentes a ser utilizado no ataque químico.

No enfrentamento e superação do problema, os participantes produzem, portanto, um avanço, visto que, diante da incerteza acerca da quantidade exata dos reagentes a ser utilizada na composição da mistura para o ataque químico ("quê que é o ataque Éverton?", linha 1; "são trinta cinco e dois >é isso?<", linha 19; "puta >e agora Luana?<", linha 22; "aí eu não sei se o ci:: se o cinco e o dois são já divididos, >eu não sei se é< trinta cinco e dois, ou se como eu faço a metade eu faço quinze cinco e dois", linhas 38-42), alcançam, ao final do segmento, a confirmação da informação que lhes impossibilitava de dar continuidade à atividade suspensa ("não. é isso mesmo", linha 187; "trinta de acético, cinco de nítrico e dois de fluorídrico", linhas 189-190). Colocados diante de um problema, os participantes conseguem, enfim, superá-lo, dado que alcançam uma resolução para os seus propósitos situados, com a qual demonstram, ao final do segmento, estarem satisfeitos, na medida em que, resolvido o problema ("é isso", linha 193; "tá", linha 194), orientam-se para retomada da atividade que vinham realizando, suspensa pelo problema emergente de sua realização, dando início ao preparo da mistura dos reagentes para o ataque químico ("=quinze,", linha 197; "quinze, dois e meio e um", linha 199).

Nesses termos, o segmento interacional de resolução de problema analisado constitui, assim, uma instância de construção conjunta de conbecimento, (a) em que Éverton e Luana se engajam conjuntamente na interação para (b) dar conta de um objeto de conbecimento (c) tornado relevante por eles próprios naquele exato aqui-e-agora da interação (ABELEDO, 2008; ABELEDO et al., 2014). Nessa empreitada, os participantes (d) produzem conjuntamente um avanço pela superação do estado inicial de dúvida acerca da informação necessária para a continuidade da atividade que vinham realizando. Pela produção conjunta desse avanço, alcançam, por sua vez, a resolução para o problema diante do qual estavam colocados, resolução com a qual (e) demonstram, ao final, estarem satisfeitos, na medida em que é de posse da informação encontrada e confirmada que encerram a atividade de resolução do problema e retomam da atividade de análise metalográfica das amostras, suspensa por um problema emergente de sua realização (KANITZ; FRANK, 2014; ABELEDO et al., 2014).

Cabe ressaltar que, embora, no início do segmento, um dos participantes sinalize ter conhecimento da existência da informação de que necessitam, mas demonstre não se recordar dela precisamente (ver Excerto 1), ao longo do dado 
aqui analisado, a necessidade de busca e confirmação dessa informação exige que os participantes co-construam de novo (do latim, desde o princípio), nesta situação particular, o conhecimento relativo à quantidade exata de cada reagente para a realização do ataque químico, de modo que possam, então, efetivamente, dar continuidade à atividade de análise metalográfica em que vinham engajados. Não se trata de tão-somente recordar uma informação, mas, sim, de construir conjuntamente, desde o princípio (de novo), um conhecimento compartilhado e preciso da informação em busca da qual estão que satisfaça os participantes e lhes possibilite retomar a atividade em que vinham engajados e que ficou suspensa com o surgimento do problema. Trata-se, portanto, de (re)construir, naquele aqui-eagora da interação, um conhecimento pela sua atualização, demandada de modo contingente naquela situação interacional e negociada interacionalmente pelo participantes como válida e boa o suficiente para a retomada da atividade em que vinham engajados ${ }^{9}$.

\section{CONSIDERAÇÕES FINAIS}

Ao tomar como foco de investigação a descrição da atividade interacional de resolução de problemas, o presente estudo busca contribuir, assim, para a descrição e compreensão de "como se dá a produção de conhecimento em atividades de fala de comunidades de práticas dedicadas a tarefas de produção de conhecimento, nas quais há colaboração entre os participantes que, até prova em contrário, se autorregulam nos seus direcionamentos para resolver problemas e alcançar seus propósitos de desenvolvimento de tecnologia" (GARCEZ, 2010, p. 7). Partimos aqui da convicção de que a descrição da atividade de resolução de problemas entre participantes de um cenário voltado para a produção de conhecimento de ponta possa ampliar o entendimento de como se dá, no plano das ações, o trabalho de construção conjunta de conhecimento, sobretudo quando, diferentemente do que geralmente ocorre em salas de aula tradicionais, não há um participante que se coloca de antemão na posição de quem domina previamente o conhecimento a ser construído.

9. Agradecemos ao(à) avaliador(a) deste trabalho pela sugestão de incluir no texto uma exposição mais detida do nosso entendimento de que a busca e confirmação de uma informação, aparentemente já sabida anteriormente, constitui, sim, nos termos do presente trabalho, uma instância de construção conjunta de conhecimento pela resolução de um problema. Agradecemos também às parceiras de pesquisa do Grupo ISE, Ingrid Frank e Fabíola Stein, pela leitura interessada e crítica do trecho acrescido. 
Acreditamos que a descrição do trabalho de construção conjunta de conhecimento pela resolução conjunta de problemas entre pesquisadores dedicados à produção de conhecimento em cenário de desenvolvimento tecnológico possa servir ainda de contraponto para que se possa seguir adiante na reflexão acerca de como se dá a aprendizagem na fala-em-interação em cenários escolares, fornecendo subsídios para se pensar e se refletir acerca de novos modos de organização e de fomento dessa produção, no cenário de sala de aula contemporânea. Nesses termos, sustentamos que os resultados da presente pesquisa possam ser utilizados para fins de interlocução pedagógica com agentes educacionais, dado o entendimento aqui proposto de que a observação e descrição da produção de conhecimento no referido Centro possam trazer contribuições para se pensar acerca de modos alternativos de organização da sala de aula que engajem os participantes na construção conjunta de conhecimento pela resolução conjunta de problemas práticos ligados às atividades pedagógicas que realizam. Esperamos assim contribuir especialmente para o exame situado de experiência vividas de produção conjunta de conhecimento para referência de pedagogias ativas organizadas por projetos de trabalho e aprendizagem.

\section{REFERÊNCIAS}

ABELEDO, M. de la O L. 2008. Uma compreensão etnometodológica da aprendizagem de língua estrangeira na fala-em-interação de sala de aula. Porto Alegre, RS. Tese de Doutorado. Universidade Federal do Rio Grande do Sul - UFRGS, 217 pp.

ABELEDO, M. de la O. L. et al. 2014. Uma compreensão etnometodológica de aprendizagem e proficiência em língua adicional. Trabalhos em Linguística Aplicada. v. 53, n. 1, p. 131-144. https://doi.org/10.1590/S0103-18132014000100007.

ANTAKI, C. 2006. Producing a 'cognition'. Discourse Studies. v. 8, nº 1, pp. 9-15.

ATKINSON, J. M.; HERITAGE, J. 1984. Structures of social action. Cambridge: Cambridge University Press/Editions de la Maison des Sciences de l'Homme, 446 pp.

BRASSAC, C.; FIXMER, P.; MONDADA, L.; WINCK, D. 2008. Interweaving objects, gestures, and talk in context. Mind, Culture, and Activity. v. 15, n 3, pp. 208-233.

BUCK INSTITUTE FOR EDUCATION. 2008. Aprendizagem baseada em projetos: guia para professores do ensino fundamental e médio. $2^{\mathrm{a}}$. ed, Porto Alegre, Artmed, 200 pp. 
FRANK, I. 2010. Constituição e superação de momentos desconfortáveis em sequências de convites à participação: a construção do engajamento na fala-em-interação de sala de aula. Porto Alegre, RS. Dissertação de Mestrado. Universidade Federal do Rio Grande do Sul - UFRGS, 170 pp.

GARFINKEL, H. 1967. Studies in ethnomethodology. Englewood Cliffs, Prentice Hall, 2888 pp.

GARCEZ, P. M. 2006. A Organização da fala-em-interação na sala de aula: controle social, reprodução de conhecimento, construção conjunta de conhecimento. Calidoscópio, v. 4, n. 1, p. 66-80.

GARCEZ, P. M. 2008. A perspectiva da Análise da Conversa Etnometodológica sobre o uso da linguagem em interação social. In: LODER, L.; JUNG, N. (Org.). Fala-eminteração social: Introdução à Análise da Conversa Etnometodológica. Porto Alegre: Mercado de Letras, 2008. p. 17-38.

GARCEZ, P. M. 2010. Fala-em-interação e comunidades de aprendizagem. Projeto de pesquisa submetido ao CNPq para renovação de Bolsa de Produtividade em Pesquisa. Manuscrito inédito. Porto Alegre: UFRGS.

GARCEZ, P. M.; SALIMEN, P. G. 2011. Pedir e oferecer ajuda para "fazer aprender" em atividades pedagógicas de encenação na fala-em-interação de sala de aula de inglês como língua adicional. In: BARCELOZ, A. M. (Org.). Linguística Aplicada: Reflexões sobre ensino e aprendizagem de Língua Materna e Língua Estrangeira. Campinas: Pontes, 2011. p. 97-117.

GARCEZ, P. M.; FRANK, I.; KANITZ, A. 2012a. Interação social e etnografia: sistematização do conceito de construção conjunta de conhecimento na fala-em-interação de sala de aula. Calidoscópio. v. 10, n. 2, p. 211-224. Disponível em: < http://revistas. unisinos.br/index.php/calidoscopio/article/view/cld.2012.102.08>. Acesso em: 20 mai. 2020.

GARCEZ, P. M.; FRANK, I.; KANITZ, A. 2012b. Produção conjunta de conhecimento em um cenário de desenvolvimento de tecnologia. Veredas, v. 16, n. 1. Disponível em: $<$ http://www.ufjf.br/revistaveredas/files/2012/10/Art-12-Garcez-Frank-e-Kanitzfinal-10.05.12formatado.pdf $>$. Acesso em: 20 mai. 2020.

GOODWIN, C. 1994. Professional vision. American Anthropologist, v. 96, nº 3, pp. 606633. 
GOODWIN, C. 1997. The blackness of black: Color categories as situated practice. In: L. RESNICK, L.; R. SÄLJÖ; C. PONTECORVO; B. BURGE (orgs.), Discourse, tools and reasoning: Essays on situated cognition. New York, Springer-Verlag, pp. 111-40

HERITAGE, J. 1984. Garfinkel and ethnomethodology. Cambridge: Polity Press, 1984.

HINDMARSH, J.; REYNOLDS, P.; DUNNE, S. 2011. Exhibiting understanding: The body in apprenticeship. Journal of Pragmatics. v. 43, $n^{0} 2$, pp. 489-503.

KANITZ, A. 2013. Resolução de problemas e construção conjunta de conhecimento na falaem-interação em cenário de desenvolvimento tecnológico. 2013. 184 f. Dissertação (Mestrado em Letras) - Programa de Pós-Graduação em Letras. Universidade Federal do Rio Grande do Sul, Porto Alegre, RS, 2013

KANITZ. A.; FRANK, I. 2014. Aprendizagem enquanto produção conjunta de conhecimento: avançando projetos e alcançando entendimentos satisfatórios na fala-em-interação. Revista Brasileira de Linguística Aplicada, v. 14, n. 1, p. 111-140. http://dx.doi.org/10.1590/S1984-63982014005000001

KOSCHMANN, T.; LEBARON, C.; GOODWIN, C.; FELTOVICH, P. 2011. "Can you see the cystic artery yet?" A simple matter of trust. Journal of Pragmatics. v. 43, n. 2, pp. $521-541$.

LODER, L. L. 2006. Investindo no conflito: a correção pelo outro construindo discordâncias agravadas. Porto Alegre, RS. Dissertação de Mestrado. Universidade Federal do Rio Grande do Sul - UFRGS, 157 pp.

LODER, L. 2008. O modelo Jefferson de transcrição: convenções e debates. In: L. L. LODER; N. M. JUNG (org.), Fala-em-interação social: introdução à análise da conversa etnometodológica. Campinas, SP: Mercado de Letras, pp. 127-162.

LODER, L. L.; JUNG, N. M. (org.). 2008 Fala-em-interação social: introdução à análise da conversa etnometodológica. Campinas, SP: Mercado de Letras.

ROGOFF, B. 2003. A natureza cultural do desenvolvimento humano. Porto Alegre, Artmed, $355 \mathrm{pp}$.

SACKS, H.; SCHEGLOFF, E. A.; JEFFERSON, G. 2003. Sistemática elementar para a organização da tomada de turnos para a conversa. Veredas. v. 7, n ${ }^{0} 1-2$, pp. 9-73, 2003. Tradução de: SACKS, H.; SCHEGLOFF, E. A.; JEFFERSON, G. 1974. A 
simplest systematics for the organization of turn-taking for conversation. Language. v. 50, pp. 696-735.

SCHEGLOFF, E. A. 1991. Conversation analysis and socially shared cognition. In: L. RESNICK; J. LEVINE; S. BEHREND (orgs.), Perspectives on socially shared cognition. Washington: American Psychological Association, pp. 150-171.

STIVERS, T.; MONDADA, L.; STEENSING, J. (orgs.). 2011. The morality of knowledge in conversation. Cambridge: Cambridge University Press, 335 pp.

SUCHMAN, L. 2000. Embodied practices of engineering work. Mind, Culture and Activity. v. 7, $\mathrm{n}^{\mathrm{O}}$ 1-2, pp. 4-18.

TE MOLDER, H.; POTTER, J. (orgs.). 2005. Conversation and cognition. Cambridge, Cambridge University Press, 284 pp.

TEN HAVE, P. 1999. Doing conversation analysis: A practical guide. Londres, Sage, 296 pp.

VAN DIJK, T. A. (org.). 2006. Discourse, interaction and cognition. Discourse Studies. v. 8, n. 1 , pp. 5-203.

WHALEN, J.; VINKHUYZEN, E. 2000. Expert systems in (inter)action: diagnosing document machine problems over the telephone. In: P. LUFF; J. HINDMARSH; C. HEATH (orgs.). Workplace studies: Recovering work practice and informing system design. Cambridge, Cambridge University Press, pp. 92-140. 


\section{ANEXO I. CONVENÇÕES DE TRANSCRIÇÃO*}

\begin{tabular}{|c|c|c|}
\hline . & (ponto final) & entonação descendente \\
\hline ? & (ponto de interrogação) & entonação ascendente \\
\hline , & (vírgula) & entonação de continuidade \\
\hline- & (hífen) & marca de corte abrupto \\
\hline$\uparrow \downarrow$ & $\begin{array}{l}\text { (flechas para cima e para } \\
\text { baixo) }\end{array}$ & $\begin{array}{l}\text { alteração do tom de voz (mais agudo: para } \\
\text { cima; mais grave: para baixo) }\end{array}$ \\
\hline : & (dois pontos) & prolongamento do som \\
\hline$\underline{\text { nunca }}$ & (sublinhado) & som enfatizado \\
\hline PALAVRA & (maiúsculas) & fala em volume alto \\
\hline${ }^{\circ}$ palavra ${ }^{\circ}$ & (sinais de graus) & fala em voz baixa \\
\hline$>$ palavra $<$ & $\begin{array}{l}\text { (sinais de maior do que e } \\
\text { menor do que) }\end{array}$ & fala acelerada \\
\hline$<$ palavra $>$ & $\begin{array}{l}\text { (sinais de menor do que } \\
\text { e maior do que) }\end{array}$ & fala desacelerada \\
\hline hh & (série de h’s) & aspiração ou riso \\
\hline.$h \mathrm{~h}$ & $\begin{array}{l}\text { (h's precedidos de } \\
\text { ponto) }\end{array}$ & inspiração audível \\
\hline$\left[\begin{array}{ll}1 & ]\end{array}\right.$ & (colchetes) & fala simultânea ou sobreposta \\
\hline$=$ & (sinais de igual) & elocuções contíguas \\
\hline$(2,4)$ & $\begin{array}{l}\text { (números entre } \\
\text { parênteses) }\end{array}$ & $\begin{array}{l}\text { medida de silêncio (em segundos e décimos } \\
\text { de segundos) }\end{array}$ \\
\hline (.) & (ponto entre parênteses) & micropausa, até $2 / 10$ de segundo \\
\hline ) & (parênteses vazios) & segmento de fala que não pôde ser transcrito \\
\hline (palavra) & $\begin{array}{l}\text { (segmento de fala entre } \\
\text { parênteses) }\end{array}$ & transcrição duvidosa \\
\hline$(($ olhando para o teto $))$ & (parênteses duplos) & descrição de atividade não-vocal \\
\hline
\end{tabular}

*Adaptado de Atkinson e Heritage (1984, p. 9-16).

Recebido: $12 / 12 / 2019$

Aceito: 15/05/2020

Publicado: 3/06/2020 